\title{
Morphometric Studies of the Axial Skeleton of the African Giant Rat (Cricetomys gambianus, Waterhouse) Part (1): Skull Typology
}

\author{
M. A. Olude* and J. O. Olopade**
}

${ }^{*}$ Department of Veterinary Anatomy, University of Agriculture, Abeokuta, Nigeria

${ }^{*}$ Department of Veterinary Anatomy, University of Ibadan, Nigeria

Received March, accepted for publication June 2010

\section{Abstract}

The purpose of this study was to investigate some aspects of the skull typology of the African giant rat. In this study, 16 adult African giant rats (Cricetomys gambianus, Waterhouse) of both sexes were used to investigate the bones of the cranial skeleton. The dimensions of excised skulls were measured directly using pre-established anatomical points. Morphometric analysis of the skulls showed important measurements and features; the intercondylar width was $1.45 \pm$ $0.02 \mathrm{~cm}$. The mean nasal length in females at $2.93 \pm 0.05 \mathrm{~cm}$ was longer than the $2.76 \pm 0.06 \mathrm{~cm}$ of male. The infraorbital foramen was large in the African giant rat with the greatest length being $0.75 \pm 0.02$ $\mathrm{cm}$ while the greatest breadth was $0.52 \pm 0.02 \mathrm{~cm}$. Maximum mandibular height and length were $2.13 \pm$ $0.02 \mathrm{~cm}$ and $3.62 \pm 0.04 \mathrm{~cm}$ respectively. Four parameters were statistically significant at $\mathrm{P}<0.05$ between both sexes and include the intercondylar width, temporal bone height, external auditory pore height and the sub arcuate fossa height;

J. Vet. Anat. these could thus serve as basis for sexual dimorphism. Major morphologic findings include the presence of a ventral mandibular foramen, a complete jugal arch and presence of jugal foramen. This work has provided morphometric information that will aid in sexual dimorphism and taxonomy of the African giant rat.

\section{Key Words}

Skull, African giant rat, Cricetomys gambianus, Waterhouse,

\section{Introduction}

The head is a very important region for animals. It is the location of vital organs as the brain, eyes, nose, tongue ear and mouth. Also, the health of an animal can be deduced from the functional state of any of these organs. The regional anatomy of the head is therefore, very important (Olopade and Onwuka, 2003). A unique craniofacial aspect of the anatomy of any animal is the skull typology of that animal with usefulness in providing a database on the bone features (Olopade and Onwuka, 2003); morphological interpreta-

Vol 3 No 2, (2010) 1 - 12 
tion of the biokinetics and biomechanics of mastication (Terai, et al., 1998), ascertaining the presence of sexual dimorphism in the skull profile (Onar et al., 2001) and in taxonomy of rodents (Dempsey, 1991).

African giant rats belong to the family Cricetidae, order Rodentia. They are nocturnal rodents and live in a variety of habitats ranging from arid areas to temperate areas usually in areas with cover from hollow trees, rock outcroppings, or burrows made by other animals (Ajayi, 1977a). The growing importance of African giant rats is under-scored from the reports on their anatomy (Oke and Aire, 1989, 1995; Oke and Oke, 1999), haematology (Olayemi et al., 2001) among others. The literature on the macro-anatomical features of the skeletal system in African giant rat is sparse. There are many macro-anatomical investigations on the skeletal sys-tem of many mammals, including the rabbit, the guinea pig and the rat (Özkan et al., 1997), the mink (Dursun and Tıpırdamaz, 1989), the badger (Hidaka et al., 1998; Dinç, 2001) the porcupine (Yılmaz et. al., 1998), the hedgehog (Özkan, 2005), the mole rat (Özkan,2007) but the skeletal systems of African giant rats have not been investtigated in detail. The goal of the present study was to investigate the cranial skeleton in the African giant rats, ascertain presence of sexual dimorphism and to contribute to baseline research information of the species.

\section{Materials and Methods}

\section{Animal care}

The care and handling of these animals conformed to the rules and guidelines issued by the University Ibadan, Nigeria.

\section{Animals and experimental model}

A total of 16 adult African giant rats (8male, 8 females) with an average body mass of $730.00 \pm 41.91 \mathrm{gm}$ were obtained from the wild through local hunters in Abeokuta, Ogun State, Nigeria, West Africa. All the animals were weighed, aged as adults using their sizes and were examined for their health status and the absence of skeletal deformities.

\section{Morphometric parameters}

Restraint was accomplished using chloroform inhalation after which they were decapitated at the atlanto-occipital joint, rapidly bled and the heads were immediately prepared using a modification of hot water maceration technique as described by Onar (1999) and Olopade and Onwuka (2003). Briefly, the heads, (placed in separate compartments for ease of identifycation) were put in water containing polycarboxylate and anionic surfactant (detergent) and soap chips and heated over $100^{\circ} \mathrm{C}$ for at least 15 minutes, tissues were removed and dissected; thereafter the skulls were put in detergent solution for at least $10-15$ minutes. Further separation of muscles and ligaments was done. The skulls were left in 0.3$0.5 \%$ Sodium Hypochlorite solution (bleach) for at least 24hours and 
removal of any remaining muscles and ligaments was done. The skulls were left in the above solution for further 6 hours, the solution being changed at least twice; the skulls were then left to dry in the sunlight.

24 parameters measured are defined in Table 1 and some are illustrated in Figures 1a-f. All of the measurements were made to the nearest $0.01 \mathrm{~mm}$ using calipers, dividers and rulers.

\section{Statistical analysis}

The data are reported as mean \pm SE (Standard error of mean). Statistical significance of experimental observations was deter-mined using t-test. The level of significance was set at $P<0.05$. All statistical analysis was done using SPSS version 15.

\section{Results}

The mean weight of the head of the male rats was $77.54 \pm 6.53 \mathrm{~g}$ while that of the females was $73.24 \pm$ $4.11 \mathrm{~g}$. The mean body masses were $762.50 \pm 67.98 \mathrm{~g}$ for males and $697.50 \pm 51.05 \mathrm{~g}$ for females. The head to body weight ratio were $11 \%$ in females and $10 \%$ in males. The cranial morphometric measurements are shown in Table 2. The values of ICW, TBH, EAPH and SAFC $(P<0.05)$ were significantly larger in males than in females; the parameters in the male animals were consistently larger than the females except for the nasal length. The nasal bone was slightly convex and the rostral portion was wider than the caudal portion; the two bones met medially at the sutura internasalis. The mean nasal length in females was longer than the males.

In male skulls (without the mandibles) $75 \%(n=6)$ the tips of both paracondylar processes reach-ed the basal level while in $25 \%(n=2)$ it was so on only one process however, both of these occurrences were absent in the female where the tips of the processes did not reach the caudobasal level. Paracondylar processes were thicker and heavier in larger animals used in this study.

The zygomatic or jugal bone occurred as a small bone pointed on both ends. It formed the zygomatic arch occurring between the zygomatic process of the maxillary bone and the temporal process of the zygomatic caudally and was present and complete in all the rats used in this study. A consistent nutrient foramen was seen on both sides i.e. left and right in $87.5 \%$ of males $(n=7)$ as against $75 \%$ on the left side $(n=6)$ and $50 \%$ on the right side $(n=4)$ of female rats. This implied that $12.5 \%$ of males $(n=1)$ had a left or right unilateral foramen. The greatest length of the infra orbital foramen in the African giant rat was $0.75 \pm 0.02 \mathrm{~cm}$ while the greatest breadth was 0.52 $\pm 0.02 \mathrm{~cm}$.

The two halves of the mandible were fused in the African giant rat with four processes of the ramus of the mandible. These included the angular process, coronoid process, 
condyloid process and the incisor alveoli. The coronoid process was thin and curved caudally; the condyloid process was shorter than the former with a ridge like articular surface oriented sagitally. The angular process bore a distinct crest laterally along its ventral edge. The crest ran to the lateral aspect of the mandibular body and ended just caudal to the mental foramen. The mandibular foramen occurred near the base of the condyloid process just dorsal to a line from the caudal edge of the third molar to the caudal end of the mandible and the transit portion from the condylar process to the angular process was signifycantly curved. A ventral mandibular foramen was observed in this present study in all the rats used in this study (Fig 1e).

The skulls of the African giant rat showed the typical rodent features with two incisors in each jaw; a wide diastema between the incisors; four cheek teeth per side in upper and lower jaws. Dental formula was constant in all rats used in this study and is given as: I 1/1 C0/0 PMO/0 $M 3 / 3$ (16). There were large vacancies in the jaws but the vacancy in the upper jaw was greater than that in the lower jaw. The average distance of the diastema in the upper jaw was $2.1 \pm 0.02 \mathrm{~cm}$ while that in the lower jaw was $1.10 \pm 0.03 \mathrm{~cm}$. A consistent Interpremaxillary foramen was found on the ventral upper jaw caudal to the upper incisors in all the rats used in this study. The incisive foramen in the African giant rat was $0.63 \pm 0.01 \mathrm{~cm}$ while the ratio of length of the incisive foramina to upper diastemal length was 0.3.

The temporal bone showed statistically significant differences between both sexes in the external auditory pore height, sub arcuate fossa height and temporal bone height all measurements being higher in males than in females.

All statistically significant values $(\mathrm{P}<$ $0.05)$ are asterisked ${ }^{*}$ in the materials and methods.

\section{DISCUSSION}

The mean weight of the head of the male rats was $77.54 \pm 6.53 \mathrm{~g}$ while that of the females was $73.24 \pm$ $4.11 \mathrm{~g}$. The body weights were heavier in males than in females but the mean head to weight ratio was higher in females. This could be due to higher bone and muscle masses in the head of rats used in this study (Olopade and Onwuka, 2003). The mean weights of the African giant rats in this study are less than reported by (Ajayi, 1977b; Ajayi et al., 1978). This size disparity may be due to the lifestyle and behavior of the sexes; females often form large groups containing many mothers and their litters while males usually remain solitary (Ajayi, 1977a; Ajayi et. al., 1978). This may lead to competition among the females and their litters for the available food, leading to delayed weight gain and growth when compared to males which are more likely to have their fill on each meal being usual lone rangers. Pucciarelli, 1981; Puccia- 
relli \& Oyhenart, 1987a \& b stated that growth of the craniofacial components in rats may be influenced by sex, breed or strain, and nutritional status and it has been reported that the craniofacial skeleton is one portion of the body that is critically affected by malnutrition (Miller and German, 1999, Fernandes et al., 2008).

The dorsal region of skull showed typical rat features. The frontal bone is slightly domed with a frontal crest and the supra orbital foramen present on the both sides. The nasal bone was slightly convex and the rostral portion was wider than the caudal portion; the two bones meet medially at a false suture as in the Wistar rat (Hebel and Strom-berg, 1976). In the mole rat, approximately one quarter of the bone is fused (Özkan, 2007).The mean nasal length in females was longer than the males. This may be a sexual advantage in the use of female rats for sniffing out land-mines and tuberculosis, as these rats are now being employed in worn torn zones and different regions of the world especially in third world countries for these purposes (Lindow, 2001). The longer nasal area may imply a larger surface area for interaction of the nasal mucosa with smell stimuli.

The mean intercanthi width was $0.93 \pm 0.03 \mathrm{~cm}$ while the intercondylar width was $1.45 \pm 0.02 \mathrm{~cm}$. The intercanthi distance was greater in males than in females, implying that the eyes were more laterally placed in males than in female. This could mean that males may be more sensitive to identify predators. This morphometric finding is consistent with the behavioural pattern (Ajayi, 1977a) and the fact that animals that are hunted preys have wider faces with more laterally placed eyes than their hunters or predators (Dyce et al., 1996).

The zygomatic or jugal bone occurred as a small bone pointed on both ends. It forms the zygomatic arch occurring between the zygomatic process of the maxillary bone and the temporal process of the zygomatic caudally. The jugal bone and zygomatic arch were similar to that described in the Wistar rat (Hebel and Stromberg, 1976), the mole rat (Özkan,2007). A consistent nutrient foramen was observed at the caudal two-third of the dorsal surface of the jugal bone in $87.5 \%$ of males and females used in this study respectively. No literature documented this occurrence in other rodents. The infra orbital foramen was large in the African giant rat with the greatest length being $0.75 \pm$ $0.02 \mathrm{~cm}$ while the greatest breadth was $0.52 \pm 0.02 \mathrm{~cm}$. In the mole rat, the greatest length and breadth were $0.46 \mathrm{~cm}$ and $0.31 \mathrm{~cm}$ respectively (Özkan,2007).

In this study, $75 \%$ of males had their paracondylar processes in contact with the caudobasal level; while $25 \%$ had unequal lengths of the paracondylar process however, both of these occurrence was absent in the female in which the paracondylar processes were above the caudobasal level (fig 1f). The para- 
condylar process is the point of insertion of the dorsal rectus capitis minor, biventer cervicis, part of the semispinalis capitis and longus capitis muscles which are involved in extension, flexion and lateral extension the head (Hebel and Stromberg 1976). This may imply that the better developed paracondylar processes in males is due to functional hypertrophy of the muscles which are probably put into more action during food hunting and other activities. These movements must have been responsible for the thicker paracondylar process in heavier animals as noted in the results. The significant difference between both sexes in ICW-intercondylar width may be as a result of the interval that separates the atlanto-occipital joint dorsally (Sisson, 1975).

The two halves of the mandible were fused cranially in the African giant rat. This is same as in the Wistar rat (Hebel and Stromberg, 1976) unlike that of the mole rats which are not fused (Ozkan, 2007). In the African giant rat there are four processes of the ramus of the mandible. These include the angular process, coronoid process, condyloid process and the incisor alveoli. The coronoid process is thin and curved caudally; the condyloid process is shorter than the former with a ridge like articular surface oriented sagitally (see fig1c). This is in consonance with the Wistar rat (Hebel and Stromberg, 1976) but differs to the report on the mole rat (Ozkan, 2007). The angular process bears a distinct crest laterally along its ventral edge. The crest runs to the lateral aspect of the mandibular body and ends just caudal to the mental foramen. The mandibular foramen occurs near the base of the condyloid process just dorsal to a line from the caudal edge of the third molar to the caudal end of the mandible (Hebel and Stromberg, 1976). The transit portion from the condylar process to the angular process was significantly curved but is linear in badgers (Hidaka et al., 1998). A ventral mandibular foramen was observed in this present study in all the rats used in this study. This has never been reported in literature in the order Rodentia (see fig1e). Reports have however been made of the presence of a lateral fenestra in the angle of the lower jaw in most dipodoids except Sicista and possibly Cardiocranius. Some specimens of Zapus and Napaeozapus lack the fenestra but it is absent in Cricetulus and Paramys (Dempsey, 1991).

Canines and premolars are absent in the order Rodentia and hence the large vacancies in the jaws (Kuru, 1999). In some rodent species, premolar teeth are present (Demirsoy,1998) but premolars were absent in the African giant rat, as in the Wistar rat (Hebel and Stromberg, 1976) and the mole rat (Vinogradov and Argiropulo, 1941). There were large vacancies in the jaws as reported by (Demirsoy, 1998) but the vacancy in the upper jaw was greater than that in the lower jaw. The average distance of the diastema in the upper jaw was $2.1 \pm$ 
$0.02 \mathrm{~cm}$ while that in the lower jaw was $1.10 \pm 0.03 \mathrm{~cm}$, in the mole, it measured $1.56 \mathrm{~cm}$ in the upper jaw and $0.52 \mathrm{~cm}$ in the lower jaw (Özkan, 2007). This large vacancy (fig 1c) may be contributory to the pouched cheek space of the oral cavity in the African giant rat. A consistent interpremaxillary foramen was found on the ventral upper jaw caudal to the upper incisors; it transmits a branch of the palatine artery. It has been observed in some cricetulus (Dempsey, 1991) but has not been reported in the Wistar rat (Hebel and Stromberg, 1976); the mole rat (Ozkan, 2007) and all dipodoids (Dempsey, 1991). The incisive foramina flank the diastema and are always inter-sected by the premaxillary-maxillary suture. The suture may intersect the foramen at the rostral, medial or caudal part of the incisive foramen (Dempsey, 1991).In the African giant rat the foramen is intersected by the suture towards its middle while in all dipodoids incisive for a-mina were intersected medially or rostrally by the suture (Dempsey, 1991). There is some variety with respect to the length of this foramen; in the African giant rat it was $6.3 \pm 0.01 \mathrm{~mm}$. The Allactaga has an average length of $7.0 \mathrm{~mm}$, Dipus and Pygeretmus 6.0 $\mathrm{mm}$, Zapus, Napaeozapus, Alactagulus, Paradipus, Stylodipus, Jaculus, and Cricetulus have lengths of $5.0 \mathrm{~mm}$, Sicista and Cardiocranius $4.0 \mathrm{~mm}$, Eozapus $3.0 \mathrm{~mm}$, and Salpingotus $2.0 \mathrm{~mm}$ (Dempsey, 1991). The ratio of length of the incisive foramina to upper diastemal length was 0.3 in the African giant rat.
However, in the Cricetulus, it had a ratio of 0.63 , Zapus 0.88 , Sicista 0.87 , Salpin-gotus 0.85, Napaeozapus 0.76 , Pygeretmus 0.72, Eozapus 0.72 , Cardiocranius, 0.69, Dipus 0.66 , Alactagulus 0.65 , Allactaga 0.65 , Paradipus 0.62 , Stylodipus 0.62 , and Jaculus 0.53 (Dempsey, 1991).

Extensive description of the rat's (Rattus rattus) on the topographic anatomy of the temporal bone of the rat has been conducted (Wysocki, 2008) and selected parts of the temporal bone were measured in the African giant rat. Unlike the domestic rat (Ratus rattus), signifycant differences were found between both sexes in three parameters which may be useful in determining which sex may be more useful in experimental investigation into the temporal region and hearing in the African giant rat. The subarcuate fossa height, external auditory pore height and the temporal bone height were greater in males than in females and this may be attributable to size differences between both sexes.

\section{References}

Ajayi, S (1977a): Field observations on the African giant rat (Cricetomys gambianus) in Southern Nigeria. East African Wildlife Journal, 15(3) 191-198.

Ajayi, S (1977b): Live and carcass weights of giant rat (Cricetomys gambianus) and domestic rabbit (Oryctalagus cuniculus). 
East African Wildlife Journal, 15(3) 223-228.

Ajayi, S.O, Tewe, E and Faturoti

(1978): Behavioral changes in

African giant rat (Cricetomys gambianus Water-house) under domestication. East African Wildlife Journal, 16(2) 137-143.

Demirsoy, A (1998): Rodentia, Yaşamın Temel Kuralları, Meteksan Anonim Şirketi Ankara pp. 621-629.

Dempsey, M.A (1991): Cranial Foramina and Relationships of Dipodoid Rodents. Dissertation. The City University of New York. NewYork, U.S.A.

Dinç, G (2001): Macro-anatomical investigations on the skele-tons of badger (Meles meles) III Skeleton axiale. Fırat Un. J. Health Sci. 15, 175-178.

Dursun, $\mathrm{N}$ and Tipirdamaz, S

(1989): Etudes macroanatomiquement sur les os dusquelette du vison (Mustela vison). J. Fac. Vet. Med. Univ. Selçuk. 5, 13-27.

Dyce, K.M, Sack, W.O and

Wensing, C.J.G (1996): Textbook of Veterinary Anatomy $3^{\text {rd }}$ edition. W.B. Saunders Company Philadelphia.

Fernandes, R.M, Abreu, A.V, Silva, R.B, Silva, D.F, Martinez, G.L, Babinski, M.A and Ramos, C.F (2008): Mater-nal malnutrition during lactation reduces skull growth in weaned rat pups: Experimental and morphometric investigation. Anatomical Science International 83, 123-130.

Hidaka, S, Matsumoto,M, Hiji, H,
Ohsako, S and Nishinakagawa, H (1998): Morpho-logy and morphometry of skulls of raccoon dogs (Nyctereutes procyonoides) and badgers (Meles meles), J.Vet. Med. Sci. 60, 161-167.

Hebel, R and Stromberg, M (1976):

Anatomy of the laboratory rat. The Wilkins and Wilkins company, Baltimore, Md. U.S.A.Library of congres cataloging in publication data.

Kuru, M. (1999): Omurgalý

Hayvanlar. Palme Yayýncýlýk, Feryal Matbaacýlýk San. Ltd. Tti., Ankara.

Lindow, M (2001): The Landmines-

Sniffing Rats of the Mozambique. Time Magazine. Retrieved on 2008-06-23

Miller, J.P and German, R.Z (1999):

Protein malnutrition affects the growth trajectories of the craniofacial skeleton in rats. J Nutr 129, 2061-9

Oke, B.O and Aire, T.A (1989): The Bulbourethral (Cowper's) gland of the African giant rat (Cricetomys gambianus-Water-house). Veterinaski. Archiv. 59, 267-274 Oke, B.O and Aire, T.A (1995): The prostate gland of the African giant rat (Cricetomys gambianus- Waterhouse). Veterinaski. Archiv. 65, 125-135.

Oke, O.A and Oke, B.O (1999):

Vaginal cytological changes during the oestrous cycle of the adult female African giant rat (Cricetomys gambianus- Waterhouse). Trop. Vet. 17, 169-180 Olayemi, F.O, Oke, O.A, Oyewale, 
J.O and Ogunsanmi, A.O (2001): The effect of season on the blood profile of the African giant rat (Cricetomys gambianus, Waterhouse). Israel Journal of Veterinary Medicine, Vol. 56 (4).

Olopade, J.O and Onwuka, S.K (2003): A preliminary investigation into some aspects of the craniofacial indices of the red Sokoto (Maradi) goat in Nigeria. Folia Veterinaria 47(2) 57-59

Onar ,V (1999): Morphometric study of the skull of the German Sherpherd Dog (Alsatian). Anat. Histol. Embryol., 28, 253256

Özkan, Z.E, Dýnç, G and Aydin, A (1997): Investigations on the comparative gross anatomy of scapula, clavicula, skeleton brachii and skeleton antebrachii in rabbits (Oryctolagus cuniculus), guinea pigs (Cavia porcellus) and rats (Rattus norvegicus). Fýrat Un. J. Health Sci. 11, 171-175.

Özkan, Z.E (2005): Macro anatomy

of axially skeleton of hedgehog. Ind. Vet. Journal. 82, 877882.

Özkan, Z.E (2007): Macroanatomical investigations on the forelimb skeleton of molerat (Spalax leucodon Nordmann). Veterinarski Arhiv 72 (2), 91-99

Pucciarelli, H.M (1981): Growth of the functional components of the rat skull and its alterations by nutritional effects. Am J Phys Anthropol 56, 33-41.

Pucciarelli, H.M and Oyhenart, E.E (1987a): Effects of maternal food restriction during lactation on craniofacial growth in weanling rats. Am J Phys Anthropol 72, 67-75.

Pucciarelli, H.M and Oyhenart, E.E (1987b): Influence of food restriction during gestation on craniofacial growth of the weanling rat. Acta Anat 129, 182-187.

Sisson, S (1975): In The Anatomy of the Domestic Animals. Vol 2. (Sissons. S and Grossman, J.D., eds) $5^{\text {th }}$ edition. W.B. Saunders Company. Philadelphia.

Terai, S, Endo, H, Rerkamnuaychoke, W, Hondo, E, Agunpriyono, S, Kitamura, N, Kuhromadu, M, Kimura, J, Hayashi, Y, Nishida, T and Yamada, J (1998): An Osteometrical study of the cranium and mandible of the lesser mouse Deer (Chevro-tain), Tragulus javanicus. J. Vet. Med. Sci. 60 (10) 1097-1105.

Vinogradov, B.S and Argiropulo, A.I (1941): Fauna of the U.S.S.R, Mammals, Zoological Institute of the Academy of Sciences of the U.S.S.R., New Series No 29, Mos-kova.

Wysocki, J (2008): Topographical anatomy and measurements of selected parameters of the rat temporal bone. Folia Morphol. 67 (2) 111-119

Yilmaz, S, Özkan, Z.E and

Özdemýr, D (1998): Macroanatomical investigations on the skeletons of porcupine $(\mathrm{Hy}$ - 
strix cristata) I. Ossa membri

thoracici. Tr. J. Vet. An

\section{TABLES}

Table 1.Parameters and the definitions of dimensions used in morphometric analysis.

\begin{tabular}{|c|c|}
\hline $\begin{array}{l}\text { PARA- } \\
\text { METER(cm) }\end{array}$ & DEFINITION \\
\hline FBL & Total length of frontal bone. \\
\hline NSL & $\begin{array}{l}\text { Overall length of the nasal bone from the rostral end of the frontal bone } \\
\text { to the rostral tip of the nasal bone. }\end{array}$ \\
\hline FNE & Length from the fronto-parietal suture to the nuchal eminence. \\
\hline $\mathrm{OCH}$ & From the nuchal crest to the lower brim of the foramen magnum \\
\hline $\mathrm{OCHW}$ & From the nuchal crest to upper rim of the foramen magnum \\
\hline IPCW & The greatest breadth of the medial ends of the jugular processes \\
\hline *ICW & Width between the lateral ends of the occipital condyles \\
\hline $\mathrm{MMH}$ & $\begin{array}{l}\text { From the base of the mandible to the highest level of the coronoid } \\
\text { process }\end{array}$ \\
\hline MDL & $\begin{array}{l}\text { Length of the lower jaw from the top of the dentary bone to the most } \\
\text { caudal projection of the angle }\end{array}$ \\
\hline MSL & Length from rostral to caudal limit of the mandibular symphysis \\
\hline DCL & $\begin{array}{l}\text { Length of the diastemal curve from the lateral end of the alveolus of the } \\
\text { lateral incisor (on the bony ridge to the cranial border of the alveolus of } \\
\text { the first molar) }\end{array}$ \\
\hline DGL & $\begin{array}{l}\text { Length of the diastemal gap from the lateral end of the alveolus of the } \\
\text { lateral incisor (on the bony ridge to the cranial border of the alveolus of } \\
\text { the } 1^{\text {st }} \text { molar). }\end{array}$ \\
\hline UDG & $\begin{array}{l}\text { Length of the upper diastemal gap from the lateral end of the alveolus } \\
\text { of the upper incisor to the cranial border of the alveolus of the } 1^{\text {st }} \text { upper } \\
\text { molar }\end{array}$ \\
\hline THPL & $\begin{array}{l}\text { From midline of the mid cranial end of the choanae to the tip of the } \\
\text { premaxillary }\end{array}$ \\
\hline POL & Length of the palate opening at the lateral ends of the hamulus. \\
\hline UMP & length of the upper molar palate \\
\hline VIF & Length of the ventral incisive foramen \\
\hline TBL & Tympanic bulla length \\
\hline
\end{tabular}




\begin{tabular}{|l|l|}
\hline TBW & Width of the tympanic bulla \\
\hline${ }^{*}$ TBH & Greatest height of the tympanic bulla \\
\hline${ }^{*} \mathrm{EAPH}$ & Height of the external auditory pore \\
\hline EAPW & Width of the external auditory pore \\
\hline${ }^{*}$ SAFH & Height of the sub arcuate fossa \\
\hline SAFW & Width of the sub arcuate fossa \\
\hline
\end{tabular}

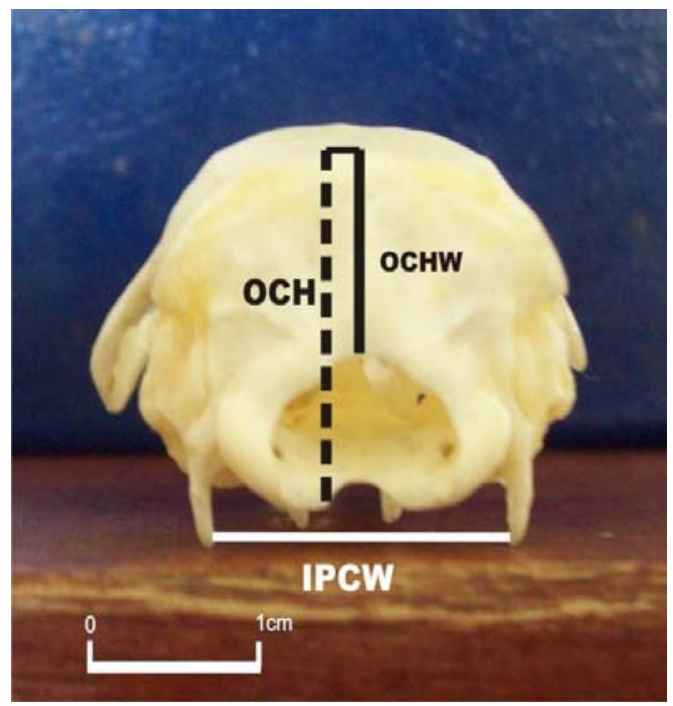

Fig (1)

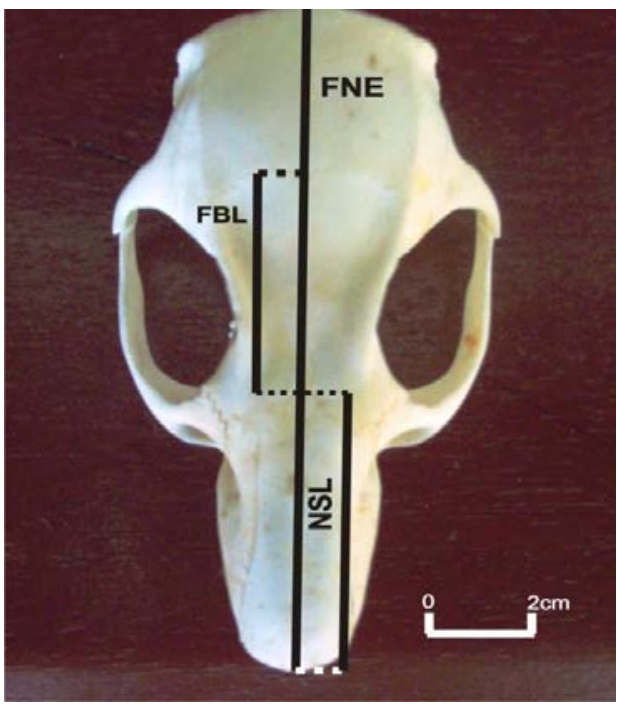

Fig (2)

Fig (1-6): African giant rat skull showing the measurements used in the morphometric analysis. Definitions of acronyms are given in Table 1.

Fig (1): Dorsal view

Fig (2): Caudal view 


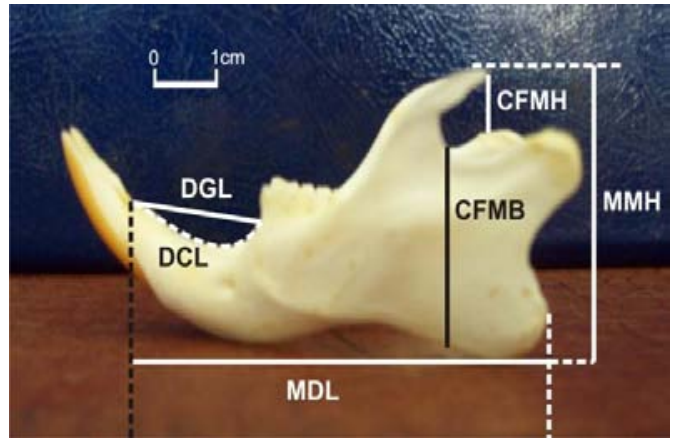

Fig (3)

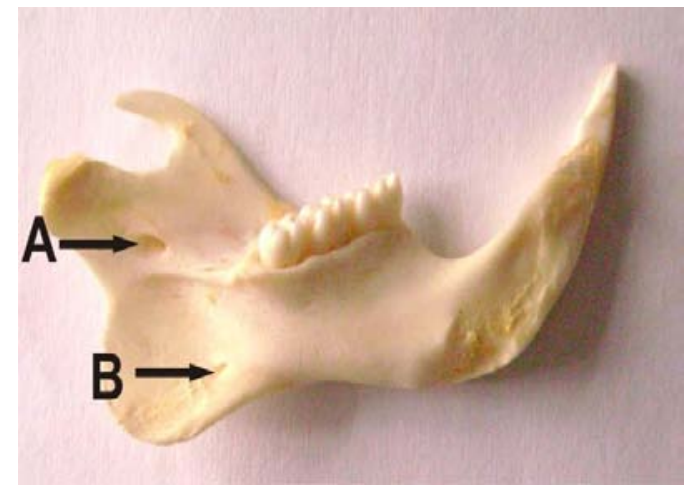

Fig (5)

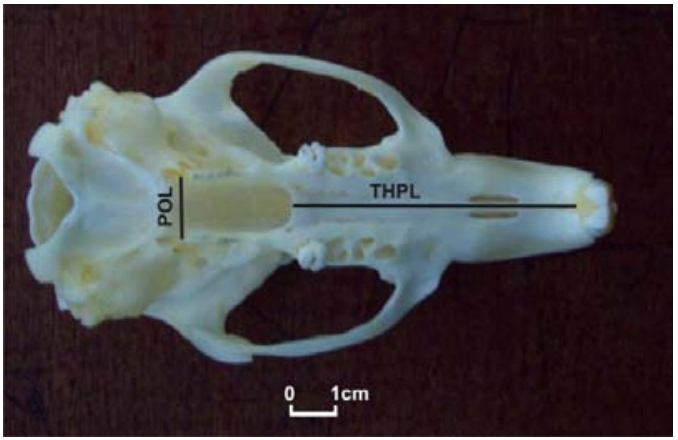

Fig (4)

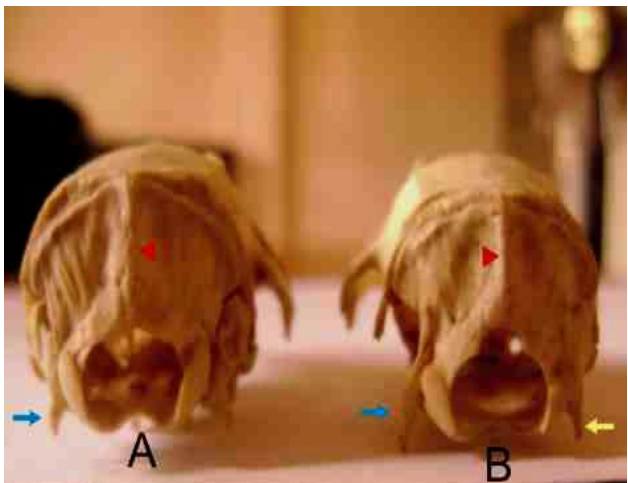

Fig (6)

Fig (3): Lateral view of the mandible

Fig (4): Ventral view

Fig (5): Medial view of the mandible; observe the dorsal mandibular foramen $(A)$ and the ventral mandibular foramen (B).

Fig (6): Comparative caudal view of two skulls; observe the external occipital crest (short red arrow heads) and the position and lengths of the paracondylar processes (blue and yellow arrows). 